\title{
Does Lineage Determine the Dopamine Phenotype in the Tadpole Hypothalamus?: A Quantitative Analysis
}

\author{
Sen Huang and Sally A. Moody \\ Department of Anatomy \& Cell Biology, Health Sciences Center, University of Virginia, Charlottesville, Virginia 22908
}

The ancestry of dopaminergic (DA) neurons in the Xenopus laevis hypothalamus was investigated by combining intracellular lineage dye injections of 16- and 32-cell blastomeres with the immunofluorescent detection of tyrosine hydroxylase at tadpole stages. At these stages, DA neurons in the hypothalamus comprise a discrete nucleus that contains from 22 to 45 cells on each side $[x=32.6 \pm 6.6$ (SD)]. The DA nucleus descends from only four of the 16-cell blastomeres. The two dorsal midline blastomeres (D1.1) are the major progenitors, and in all embryos studied they contributed to the DA nucleus. The two dorsal lateral blastomeres (D1.2) contribute to the DA nucleus in only about half of the embryos. Thus, the DA nucleus descends only from a discrete group of progenitors, and the participation of some of the progenitors in the DA lineage is only probabilistic. The number of DA neurons generated by the same blastomere varied greatly in different animals. This variation in cell number correlated with the degree of coherence and the density of the clone in the hypothalamus, rather than with clonal ancestry. Bilateral deletion of the major 32-cell progenitor (D1.1.1) resulted in a nearly complete restitution of the DA nucleus in $74 \%$ of the embryos that successfully completed gastrulation and neurulation. In the rest, the hypothalamus was smaller than normal or missing, and the DA nucleus was significantly reduced in size or absent. These results show that the DA nucleus can be restored after its normal lineage is deleted, but complete regulation is not always accomplished. Several blastomere progenitors dramatically altered their contribution to the DA nucleus after D1.1.1 ablation, including two blastomeres that normally do not contribute to the DA lineage. Thus, the fate to produce DA neurons is not determined at cleavage stages.

The time at which embryonic cells become committed to a neural fate, the steps by which neural cells assume particular phenotypes, and the role that cell lineage plays in these decisions are important issues in developmental neurobiology. The influence that a cell's mitotic history has on phenotype differentiation has been most completely studied in invertebrates in which there are relatively small numbers of cells and for which techniques

\footnotetext{
Received June 18, 1991; revised Oct. 11, 1991; accepted Nov. 11, 1991.

This work was supported by NIH Grant NS23158 and a grant from the Amyotrophic Lateral Sclerosis Association. We thank Drs. Steven Klein and Marilyn Fisher for their critical reviews of the manuscript.

Correspondence should be addressed to Dr. Sally A. Moody, Department of Anatomy \& Cell Biology, Box 439 Health Sciences Center, University of Virginia, Charlottesville, VA 22908.

Copyright (C) 1992 Society for Neuroscience $0270-6474 / 92 / 121351-12 \$ 05.00 / 0$
}

that allow direct monitoring of mitotic events are available. In several invertebrates, there is evidence that the ancestry of a cell can affect its phenotype via at least three mechanisms (Kenyon, 1985; Stent, 1985; Davidson, 1990). (1) A precursor may become committed to produce a clone of phenotypically similar cells. Examples include the nematode intestine, some muscle and some gonadal cells (Kenyon, 1985), vertebrate blood cells (Nicola and Johnson, 1982), and some ascidian muscle cells (Nishida and Satoh, 1985). (2) The position of a cell within the mitotic pattern itself may specify phenotype. For example, postembryonic nematode motoneurons are determined by their positions in the P-cell sublineages (White et al., 1982), and the lineal position of a grasshopper ganglion mother cell determines the neuronal types of its daughters (Doe and Goodman, 1985; Doe et al., 1985). (3) Finally, lineage may place a cell in the correct position in a tissue so that it comes under the influence of localized intercellular signals that directly induce a specific phenotype. For example, six ventral hypodermal cells in the nematode vulva (P3.p-P8.p) are equivalent in lineage and fate, but the final phenotypes of their descendants are determined by their position with regard to an anchor cell that is thought to secrete a morphogen (Sulston and White, 1980; Sternberg and Horvitz, 1984).

Recent cell fate studies in the vertebrate CNS, using either direct injection of progenitors (e.g., Holt et al., 1988; Wetts and Fraser, 1988; Hartenstein, 1989), or injection of recombinant retrovirus into the ventricles (e.g., Price et al., 1987; Turner and Cepko, 1987; Gray et al., 1988; Leber et al., 1990), have questioned whether lineage plays a similar role in more complex animals. Both techniques demonstrate that neuroepithelial progenitors produce multiple phenotypes, often including both neurons and glia (Galileo et al., 1990), and thus rule out that precursors committed to a single phenotype are common in vertebrate CNS development. [The one possible exception is mouse cortical glia (Luskin et al., 1988).] However, these techniques are not able to monitor the result of every mitotic division or label the exact same progenitor in many different animals. Therefore, the possibility that a cell's position within the mitotic tree influences its phenotype cannot yet be excluded.

In the present study, we test whether lineage restricts neuronal fate by marking clones from "identified" cleavage stage blastomeres in frog embryos, whose cleavages are identical among the experimental population. Although these blastomeres give rise to thousands of descendants dispersed in numerous organs (Hirose and Jacobson, 1979; Jacobson and Hirose, 1981; Dale and Slack, 1987; Moody, 1987a,b), the cleavage stage frog embryo provides the experimental advantage of allowing one to mark the exact same progenitor in a large number of animals. 


\section{EXPERIMENTAL PROCEDURES}

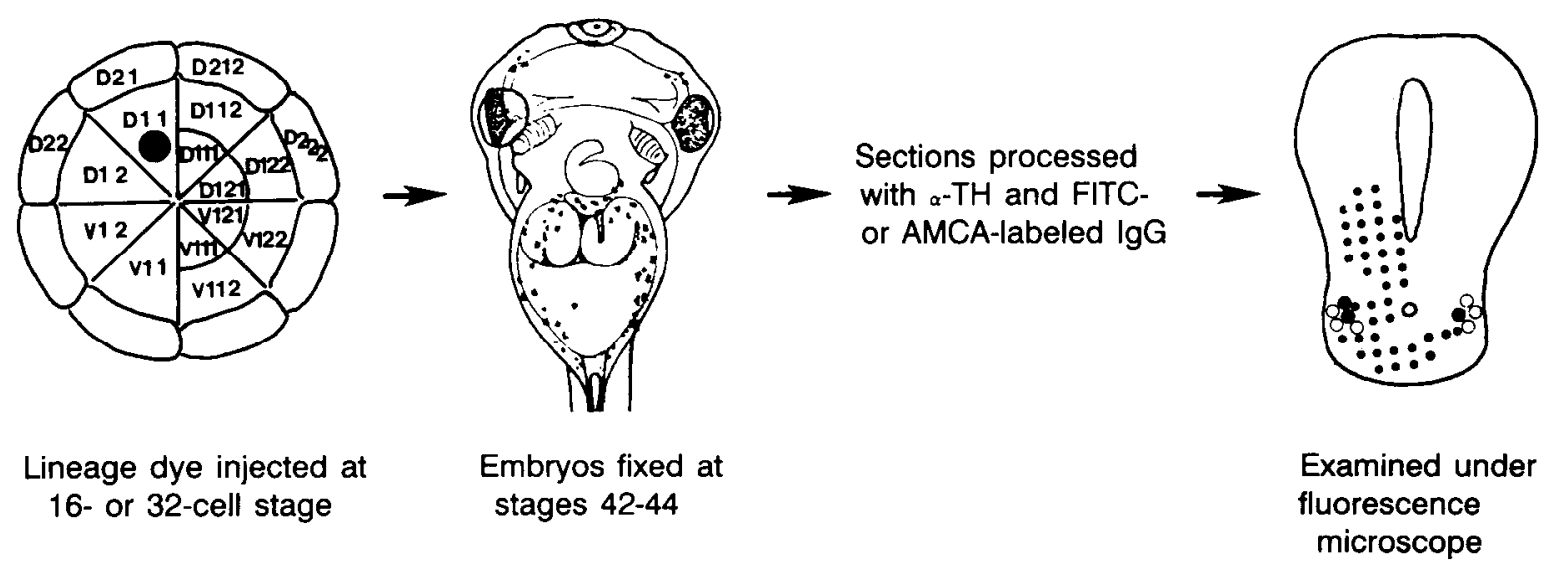

Figure 1. Outline of the experimental procedure. The nomenclature of 16-cell blastomeres is given on the left and of 32-cell blastomeres is given on the right of the cleavage stage embryo. Only those blastomeres that were injected in this experiment are labeled. The big solid circle represents TRA injected into one blastomere. In the far right diagram, which represents a frontal section of the diencephalon, solid circles indicate the location of members of the TRA-labeled clone, open circles indicate TH-positive cells, and dense-cored circles indicate double-labeled (DA-TRA) cells.

This technique obviates the concern with studies that randomly initiate clones in the embryonic CNS that one cannot monitor the extent of population variation in the lineage because the same neuroepithelial progenitor is not labeled in many different animals. The wide range of clone sizes and constituent phenotypes observed in retrovirally labeled clones, for example, could be the result of the randomness of the viral infection of the neuroepithelial cells, rather than randomness in lineage. In the frog, however, we can test whether the clone derived from an identified progenitor varies among individuals. Although many reports have argued that multiple phenotypes within a clone indicates that lineage plays little role in neural development, a necessary test is whether the genealogical lineages are invariant from one individual to the next. For example, different nematode progenitors produce clones of various sizes that contain multiple phenotypes; it is the fact that the mitotic history of each cell is invariant, rather than the lack of diversity of phenotypes within a clone, that argues that lineage has an important role in cell phenotype determination (Sulston et al., 1983).

We have addressed this issue in a vertebrate by focusing on a small, discrete cluster of dopaminergic (DA) neurons in the tadpole hypothalamus. In tadpoles and adult amphibians, the primary location of DA neurons is in the hypothalamus, as demonstrated by immunocytochemical (Franzoni et al., 1986; Moody and Huang, 1990) or induced histofluorescence techniques (Terlou and Ploemacher, 1973; Sims, 1977; Lamas et al., 1988). The DA neurons in the adult amphibian hypothalamus are concentrated in three major nuclei: the preoptic recess organ, the paraventricular organ, and the nucleus infundibularis dorsalis (Terlou and Ploemacher, 1973). In the early tadpole (stage 43/44), the DA neurons form a continuous column of cells, which separate into the three distinct adult DA nuclei around stage 50 (Moody and Huang, 1990). Although these nuclei do not have exact homologs in the mammalian brain, the distribution of DA cell bodies and their axonal projections in the mammalian hypothalamus are very similar to those described in amphibians (Parent, 1979).
The stage $43 / 44$ tadpole DA nucleus is an ideal subject for lineage analysis because it consists of only $22-45$ cells on each side of the hypothalamus (Moody and Huang, 1990) and therefore is small enough that theoretically all of the neurons could descend from a single blastomere, according to a clonal lineage pattern. Furthermore, the neurons of this nucleus can be identified unambiguously by neurotransmitter immunohistochemistry. Combining fluorescent lineage tracers with immunofluorescence of a cell phenotype marker is more accurate than relying solely on morphology to identify members of a clone (e.g., Blair et al., 1990; Galileo et al., 1990). The small number of neurons in the DA nucleus also allows us to count how many of these cells descend from the same progenitor in many different embryos, permitting us to ask whether there is any evidence that lineage has a role in the control of cell number. Finally, deletions of the major DA neuron progenitor make it possible to test the state of commitment of blastomeres to the generation of this nucleus.

\section{Materials and Methods}

Collection and injection of embryos. The procedure for collection and injection of embryos has been described in detail previously (Jacobson and Hirose, 1981; Moody, 1987a, 1989). Briefly, the jelly coat was chemically removed from naturally fertilized Xenopus laevis eggs, and those two-cell stage embryos in which the first cleavage furrow bisected a palely pigmented crescent on the dorsal animal hemisphere were selected. This procedure allows the accurate identification of the dorsal and ventral hemispheres at later stages (Klein, 1987; Masho, 1990). At 16 - and 32-cell stages, only the embryos with stereotypic radial cleavages (type X; Jacobson, 1981; Moody, 1987a,b) were used for lineage dye injection. It is known that different cleavage furrow patterns give rise to clones with different composition (Jacobson, 1981; Masho, 1988; Moody and Kline, 1990). By selecting our experimental group to consist of animals with identical, invariant lineages, at least during the early cleavage of cycles, identical progenitors were labeled. In these animals, we could test whether clone positions and sizes are determinate.

About $1 \mathrm{nl}$ of $0.5-1 \%$ Texas red-dextran amine (TRA; Molecular Probes) was pressure injected into the identified blastomeres (the nomenclature of blastomeres is that of Hirose and Jacobson, 1979; Jacobson and Hirose, 1981). In this experiment, only those blastomeres 

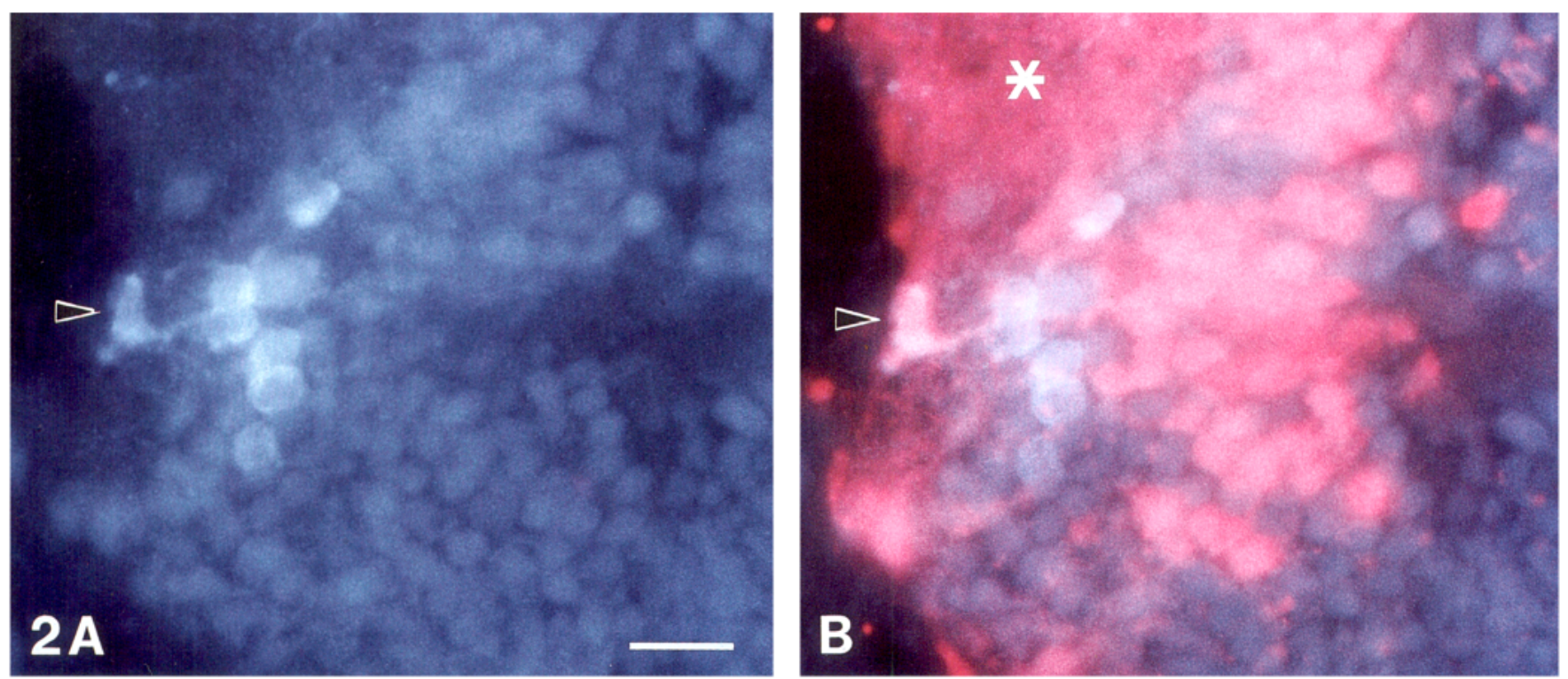

Figure 2. A pair of photomicrographs showing both TH immunofluorescence and TRA lineage dye. A, TH-positive neurons labeled with AMCA fluoresce blue under UV excitation. B, A double-exposed micrograph showing blue TH-positive cells and red cells that are members of a clone descended from D1.2. One cell (arrowhead) is double labeled. Asterisk indicates the TRA-labeled axon tract. Scale bar, $25 \mu \mathrm{m}$.

known to contribute descendants to ventral forebrain (Dale and Slack, 1987; Moody, 1987a,b) received TRA injections (Fig. 1, Table 1). Embryos were raised in the dark in a $20^{\circ} \mathrm{C}$ incubator for about $5 \mathrm{~d}$, and fixed by immersion in $0.1 \mathrm{M}$ phosphate-buffered saline containing $4 \%$ paraformaldehyde and 3\% sucrose at stage 43/44 (Nieuwkoop and Faber, 1964). At these stages, the tyrosine hydroxylase (TH)-immunoreactive cells form a coherent cell cluster in the hypothalamus (Moody and Huang, 1990) and the lineage dye is still clearly identifiable in the tissue (Fig. 2). Although additional DA neurons are subsequently added to the population, the fluorescent lineage tracer begins to fade from some cells, as determined by counts of double-labeled cells at later stages (data not shown). Therefore, in order to combine these two techniques it was necessary to analyze the early stages of DA nucleus differentiation.

Blastomere deletions. Bilateral D1.1.1 blastomeres (Fig. 1) were removed from some embryos after one animal hemisphere blastomere had been injected with TRA. In order to find any new sources of DA neurons, all animal pole blastomeres and the dorsal, marginal vegetal blastomeres (D2.1.2, D2.2.2) were marked with lineage tracer. After injection, the embryo was transferred to $50 \%$ Steinberg's solution, the vitelline membrane removed, and both D1.1.1 blastomeres gently pulled free with sharpened forceps. Any cellular debris left in the wound was removed. Any embryo that extruded cellular debris at any time through the end of gastrulation was discarded from further analysis because the debris indicates surgical damage, which can compromise the ability of an embryo to regulate (e.g., Roux, 1888). A detailed account of this procedure has been published (Gallagher et al., 1991).

Tissue processing and immunoreaction. The embryos weree cut in 14 $\mu \mathrm{m}$ transverse and sagittal serial sections with a cryostat. The slides were processed for indirect immunofluorescent detection of $\mathrm{TH}$ according to protocols previously described (Moody et al., 1989). TH antibody (Eugene Tech) was applied at a 1:400 dilution for about $48 \mathrm{hr}$ at $4^{\circ} \mathrm{C}$. Fluorescein isothiocyanate (FITC)-conjugated (Hyclone Lab) or 7-amino-4-methylcoumarin-3 acetic acid (AMCA)-conjugated (Jackson Immunoresearch Labs) goat anti-rabbit IgG was applied at a 1:20 dilution for $2 \mathrm{hr}$ at $20^{\circ} \mathrm{C}$.

Fluorescent microscope examination and data collection. The cells labeled by lineage dye injection (TRA) and the DA neurons labeled with FITC or AMCA were identified with an epifluorescence microscope (Fig. 2). Most of the sections were photographed twice: once for TH labeling (green or blue fluorescence) and once for TRA labeling (red fluorescence). The number of DA neurons in each section was counted at $500 \times$ and the DA-TRA double-labeled cells were positively identified by repeatedly shifting the filter sets back and forth, and checking the photographic records. Only the cells with identifiable nuclei were
For each blastomere, the data were collected from 10-15 embryos. The number of cells in normal and in D1.1.1-ablated embryos was compared by the Student's $t$ test.

In order to compare the counts of the DA neurons in each clone with the total size of that clone in the hypothalamus, the number of cells in the clone was quantified. Serial frontal sections through the DA nucleus were photographed at $50 \times$. A grid, whose squares each defined $18 \times$ $18 \mu \mathrm{m}^{2}$ of the actual tissue, was used to measure the area of the hypothalamus. The number of TRA-labeled cells was counted within this area and expressed as cells/area of hypothalamus. These values were compared to the number of DA neurons in the clone by linear regression.

\section{Table 1. Blastomeres that give rise to DA neurons in the ventral} forebrain

\begin{tabular}{lccccc} 
Blastomere & $N$ & $\mathrm{Fb}^{a}$ & $\mathrm{Hy}^{b}$ & $\mathrm{TH}^{c}$ & $\mathrm{TH} / \mathrm{Hy}^{d}$ \\
\hline D1.1 & 15 & $100 \%$ & $100 \%$ & $100 \%$ & $100 \%$ \\
D1.1.1 & 12 & $100 \%$ & $100 \%$ & $100 \%$ & $100 \%$ \\
D1.1.2 & 15 & $100 \%$ & $80.0 \%$ & $53.3 \%$ & $66.7 \%$ \\
D1.2 & 12 & $100 \%$ & $58.3 \%$ & $50.0 \%$ & $85.8 \%$ \\
D1.2.1 & 11 & $100 \%$ & $36.4 \%$ & $27.3 \%$ & $75.0 \%$ \\
D1.2.2 & 10 & $72.7 \%$ & $40.0 \%$ & $40.0 \%$ & $100 \%$ \\
D2.1 & 17 & $23.5 \%$ & $11.8 \%$ & 0 & 0 \\
D2.1.2 & 15 & 0 & 0 & 0 & 0 \\
D2.1.1 & 11 & 0 & 0 & 0 & 0 \\
V1.2 & 16 & $37.5 \%$ & $6.3 \%$ & 0 & 0 \\
V1.2.1 & 16 & $37.5 \%$ & 0 & 0 & 0 \\
V1.2.2 & 10 & $20.0 \%$ & 0 & 0 & 0 \\
V1.1 & 10 & $10.0 \%$ & 0 & 0 & 0 \\
V1.1.1 & 11 & 0 & 0 & 0 & 0 \\
V1.1.2 & 13 & 0 & 0 & 0 & 0 \\
\hline
\end{tabular}

${ }^{a}$ Percentages of cases that had TRA-labeled cells in the forebrain.

${ }^{b}$ Percentages of cases that had TRA-labeled cells in the hypothalamus.

' Percentages of cases that contained double-labeled TH-positive cells.

${ }^{d}$ Percentages of cases with TRA-labeled cells in the hypothalamus that contained double-labeled TH-positive cells. 

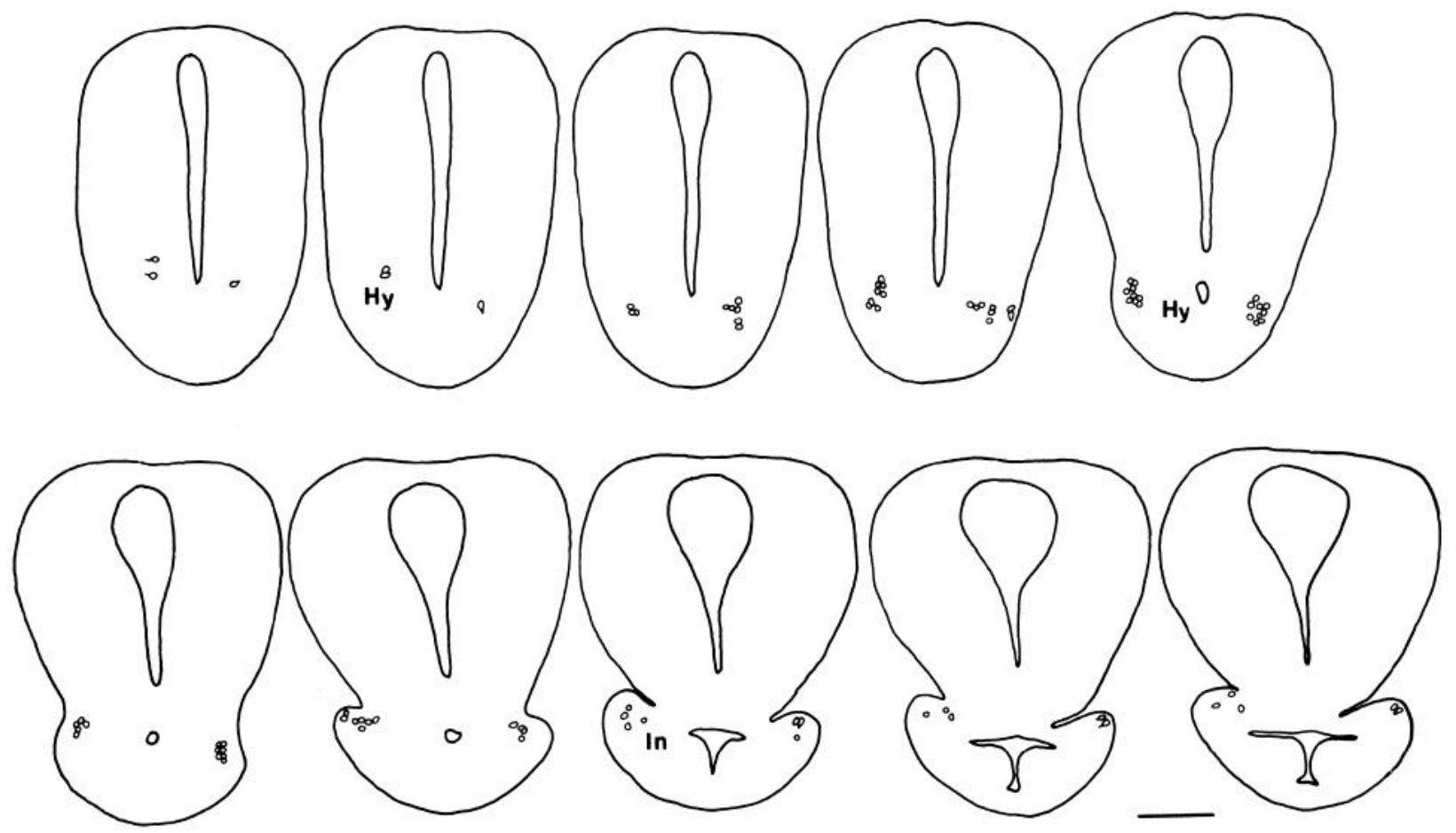

3A
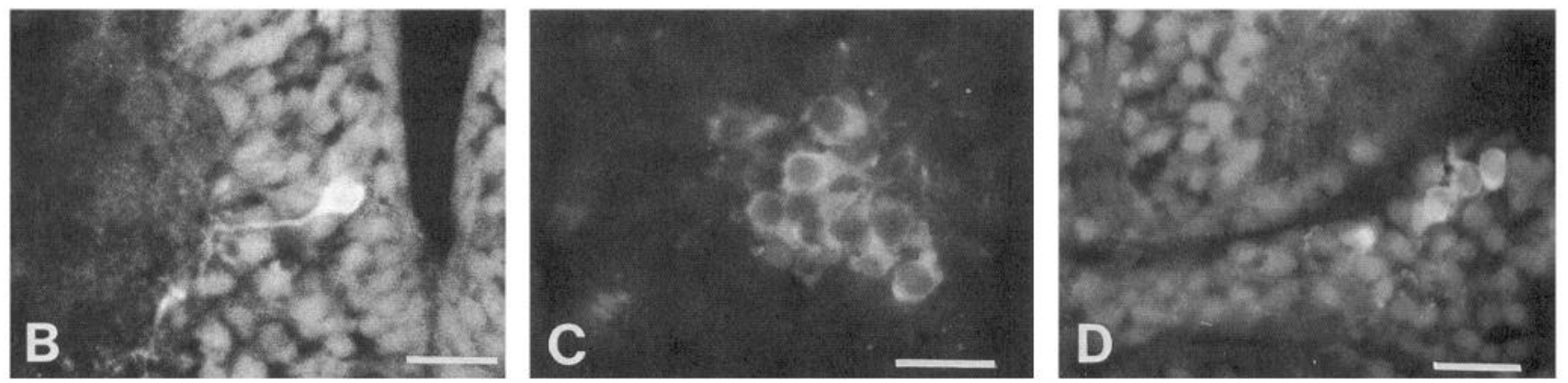

Figure 3. A, Camera lucida drawings of serial frontal sections showing the distribution of DA neurons (small open circles) in the hypothalamus $(H y)$ and infundibulum (In) of a stage 44 embryo. From rostral (top left) to caudal (bottom right), the DA neurons form a coherent, continuous cell cluster. $B-D$, Examples of DA neurons at different regions of the hypothalamus. $B$, Photomicrograph of a rostral DA neuron (e.g., in the first section of the top row in $A$ ) located in the intermediate zone. Note the laterally oriented axon. $C$, DA neurons in the middle region of the hypothalamus (e.g., the last section of the top row in $A$ ) form a coherent cell cluster. $D$, Caudally in the infundibulum (e.g., the last sections in the bottom row of $A$ ) DA neurons are restricted to the dorsolateral margin. Scale bars: $A, 100 \mu \mathrm{m} ; B-D, 25 \mu \mathrm{m}$.

\section{Results}

TH-positive cells form a discrete, coherent cell cluster in the hypothalamus

At stage 43/44, DA neurons in the hypothalamus form a discrete cluster (80-125 $\mu \mathrm{m}$ rostral-caudal dimension; Fig. $3 A$ ). Most rostrally, there usually was only one or two DA neurons, which had laterally oriented processes in the intermediate zone (Fig. $3 B$ ). Proceeding caudally, more and more DA neurons were located laterally (Fig. $3 C$ ). Most caudally, the number of DA neurons decreased again, and the cells were located along the dorsal surface of the infundibulum (Fig. 3D). Most DA neurons were clustered as close neighbors, with round or oval cell bodies and some short processes. The few cells that were distant from

Figure 4. Transverse sections illustrating the different distribution patterns of TRA-labeled cells in the stage 43 forebrain, including the infundibulum $(I n)$. Asterisks indicate the labeled axon tracts. A, A typical distribution of D1.1.1 clone with dense ventral labeling and many contralateral cells. $B$, In other cases of D1.1.1 clones, the TRA-labeled cells are more dorsally located and scattered in small numbers in the hypothalamus. $C$, Usually, the descendants of D1.2 and its daughters are located in the dorsal and intermediate forebrain. $D$, In some cases, the D1.2 clone shifts ventrally and enters the hypothalamus. Scale bars, $100 \mu \mathrm{m}$. 

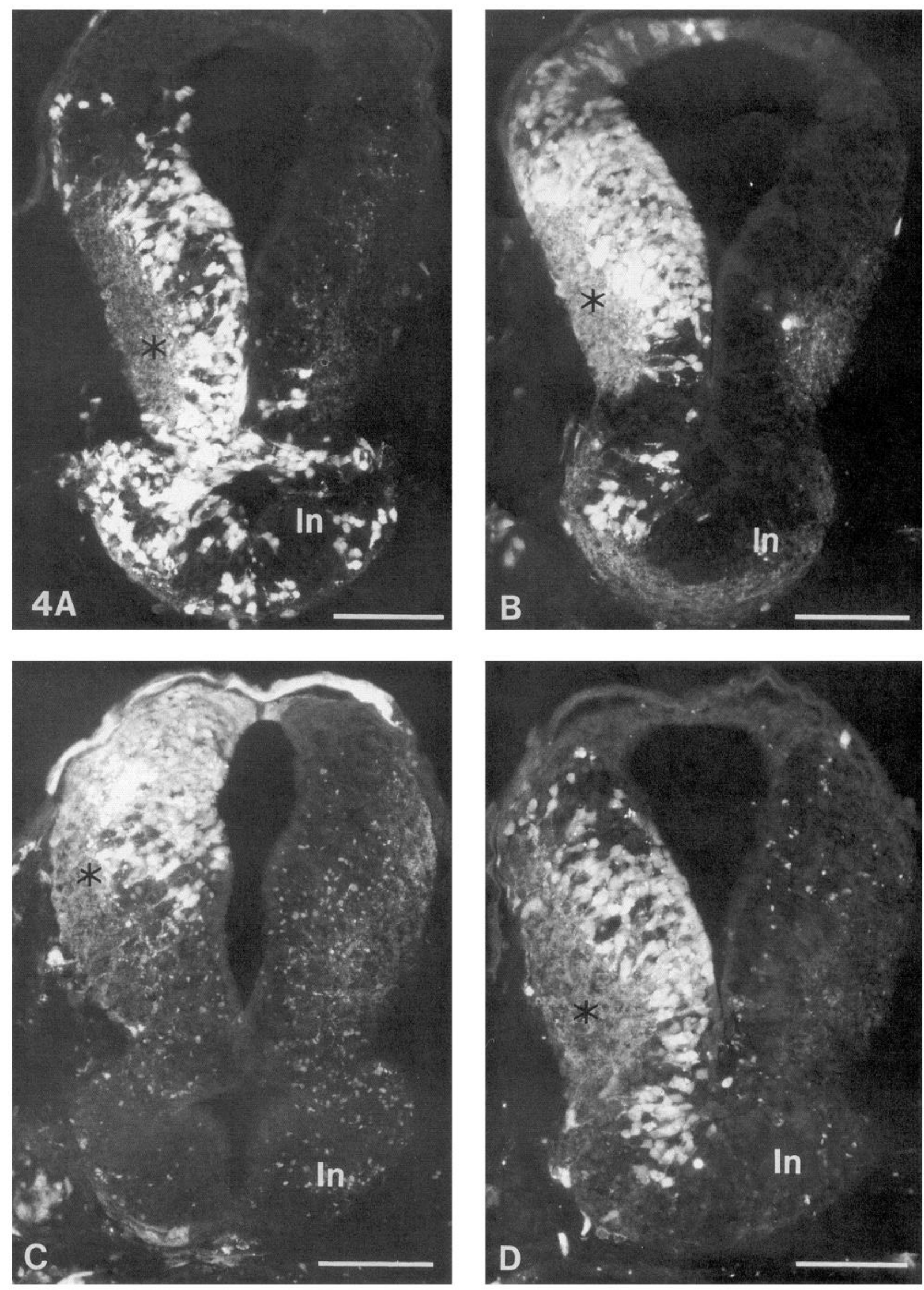

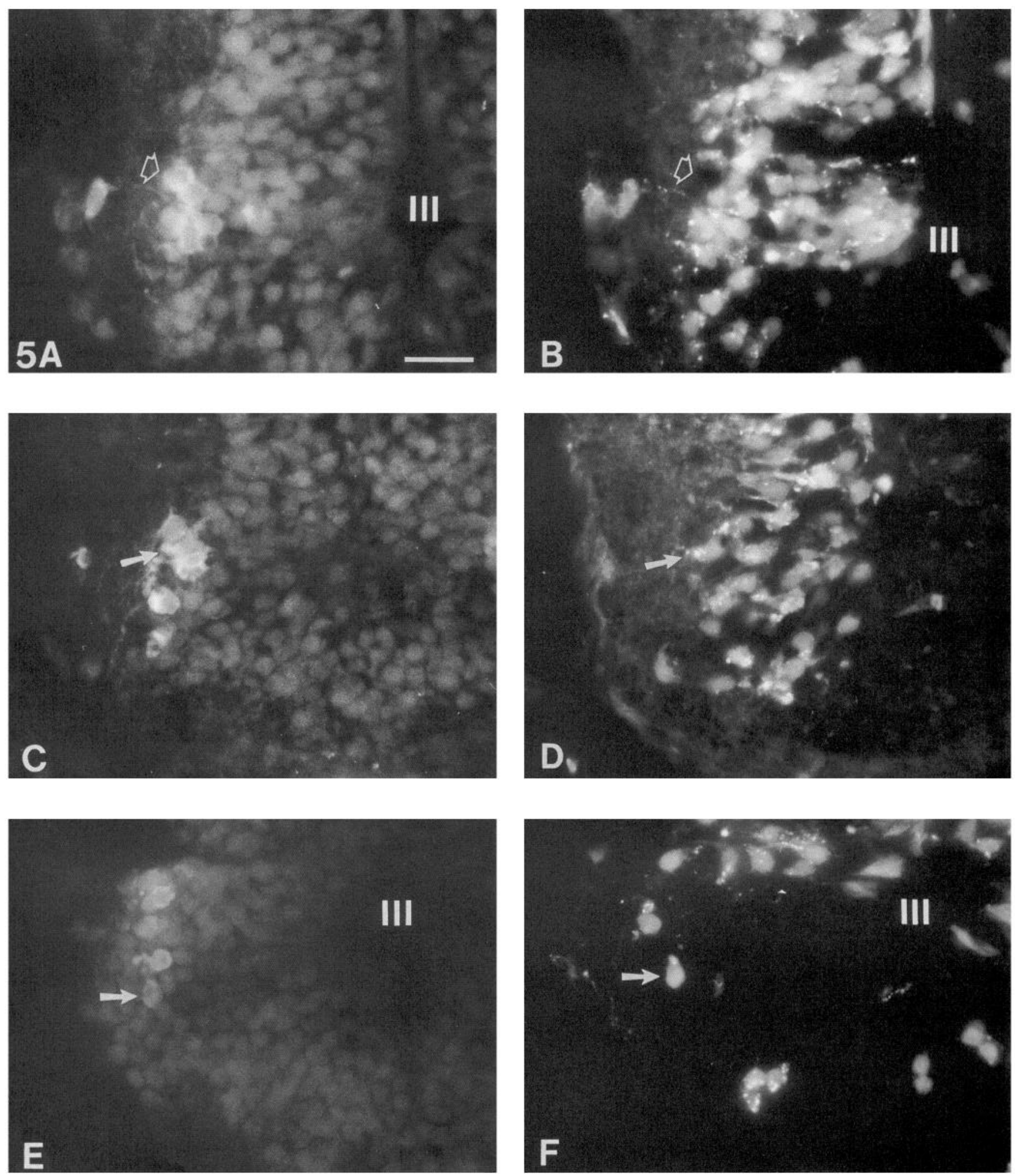

Figure 5. Pairs of photographs, taken of the same microscopic fields, showing the positional relationship between the DA neurons (left) and the TRA-labeled cells (right). $A$ and $B$, A coherent pattern after D1.1.1 injection. The TRA cell clone overlaps the TH nucleus so that all but one (open arrows) of the TH cells in the nucleus are double labeled. $I I I$, third ventricle. $C$ and $D$, TRA-labeled and unlabeled cells are intermixed extensively after D1.2 injection. On this section, only one cell (arrows) is double labeled, but in the entire DA nucleus nine cells were labeled. $E$ and $F$, TRAlabeled cells are scattered among unlabeled cells after D1.1.1 injection. In most of the sections of scattered clones, there are no double-labeled cells. In this embryo, there were two double-labeled cells, one of which appears in this section (arrows). III, third ventricle. Scale bar, $25 \mu \mathrm{m}$. 
the cluster resided just beneath the pial surface and usually appeared more differentiated, having smaller nuclei, multipolar cell bodies, long processes, and brighter immunofluorescence. On average, each side of the embryo had 32.6 DA neurons $( \pm 6.6$ [SD]; $N=96$ DA nuclei from 48 embryos).

\section{Blastomeres that contribute cells to hypothalamus}

Previous fate maps showed that several blastomeres give rise to descendants in the ventral forebrain (Jacobson and Hirose, 1981; Dale and Slack, 1987; Moody, 1987a,b), and we confirm those reports (Table 1). D1.1 and its daughters usually give rise to progeny bilaterally in the ventral forebrain (Fig. $4 A, B$ ). In all cases, there were labeled D1.1 descendants in the hypothalamus, some of which belonged to the DA nucleus (Table 1). D1.1.1, the animal pole daughter of D1.1, also contributed to hypothalamus in all embryos, and all of its clones contained cells in the DA nucleus. However, D1.1.2, the equatorial daughter of D 1.1 , contributed to hypothalamus in only $80 \%$ of embryos; $85 \%$ of these clones contained cells in the DA nucleus. D1.2 and its daughters usually generated cells that resided mostly in the dorsal and intermediate forebrain, and they contributed to contralateral forebrain less than D1.1 (Fig. 4C,D). Although nearly all embryos in which D1.2 or its daughters were labeled had at least a few cells in the forebrain, less than half had progeny in the hypothalamus (Table 1). In most of the cases in which descendants of D1.2 and its daughters were in the hypothalamus, at least some were DA neurons. Other blastomeres give rise to cells in the forebrain in some cases (Table 1; Moody, $1987 \mathrm{a}, \mathrm{b})$, but in none of these was a TH-positive desccndant observed. In summary, D1.1 and its animal pole daughter (D1.1.1) consistently give rise to DA neurons, but the other blastomeres that can produce DA neurons only do so occasionally.

\section{The spatial relationship between $D A$ neurons and the TRA clones}

The clones from a given blastomere characteristically are restricted to certain broad areas of the forebrain (Fig. 4A,C). However, the coherence of the clones derived from the same blastomere varies from embryo to embryo. For example, when D1.1.1 is injected, the members of its clone can be coherent or widely scattered in the same region of the hypothalamus (compare Fig. $5 B$ to $5 F$ ). The number of DA neurons contained in a clone correlated with the coherence of the constituents of the clone rather than with which progenitor was labcled. When the clone of the injected blastomere formed a coherent patch in the intermediate zone of the hypothalamus, large numbers of DA neurons were members of the clone (Fig. $5 A, B$ ). When the TRAlabeled cells and unlabeled cells were intermixed evenly in a mosaic pattern (Fig. $5 C, D$ ), the injected blastomere contributed to intermediate numbers of DA neurons. When the TRA-labeled cells were sparsely scattered among unlabeled cells, the injected blastomere contributed only a few DA neurons (Fig. $5 E, F)$.

In addition, the density of the clone predicts the number of DA neurons in the clone. For example, the progeny of D1.1 and its daughters were distributed at a fairly high density throughout the hypothalamus in many cases (Figs. $4 A, 5 B$ ), but in other cases they were scattered more sparsely (Fig. $4 B$ ). The progeny of D1.2 and its daughters typically resided in the dorsal and intermediate ipsilateral forebrain (Fig. 4C), but in a few cases they extended ventrally into the hypothalamus (Figs. $4 D, 5 D$ ).

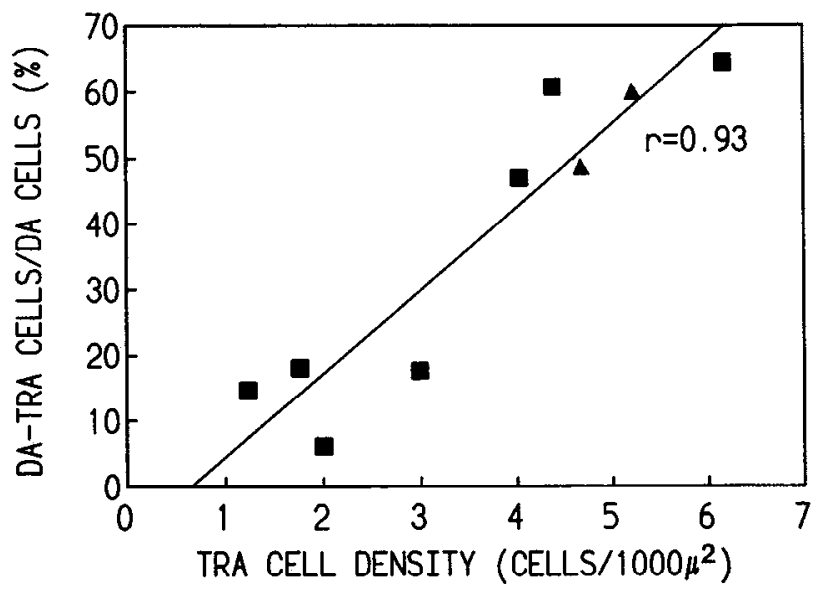

Figure 6. Regression line indicates a significant correlation between the density of the TRA clone in the hypothalamus and the percentage of DA neurons that are double labeled. The clones used for quantification descended from D1.1.1 (squares) and D1.1.2 (triangles). These results indicate that the number of DA cells produced by each blastomere is related to the density of progeny in the hypothalamus rather than to ancestry.

These observations suggest that the number of DA neurons produced by a particular blastomere in different embryos relies more on the density at which the blastomere populates the hypothalamus (Figs. 4,5 ) than on the blastomere of origin. To test statistically whether the density of the clone in the hypothalamus predicted the number of DA ncurons in the clone, we quantified the number of TRA cells in the hypothalamus and compared this value to the percentage of DA-TRA cells in the DA nucleus for blastomeres D1.1.1 and DI.1.2. The number of DA neurons produced by these blastomeres was significantly correlated with how densely its clone populated the hypothalamus ( $r=0.93$; Fig. 6$)$, rather than with clonal origin.

\section{Quantitative analysis of $D A-T R A$ cells}

In order to test whether the different blastomeres that give rise to DA neurons produce a determined number of cells of the same phenotype, we counted the number of DA-TRA cells in each specimen. The average number and the range of doublelabeled DA-TRA cells that descended from each blastomere are shown in Table 2. On the average, D1.1 and its daughters are the major progenitors of DA neurons. For example, D1.1 produces $41 \%$ of the ipsilatcral DA ncurons and $21 \%$ of the contralateral neurons. However, for each blastomere there was a large variation between specimens, as indicated by the large SD of the mean number of cells and the wide ranges of the percentage of the total number of DA neurons produced in each specimen (Table 2). For example, in different embryos D1.1 produced from $8 \%$ to $87 \%$ of the ipsilateral nucleus and from $7 \%$ to $69 \%$ of the contralateral nucleus; D1.2 contributed from $8 \%$ to $46 \%$ of the ipsilateral DA nucleus (Table 2). These data demonstrate that identified blastomere progenitors are not determined to produce a set number of DA neurons.

\section{Deletion of the major 32-cell progenitor}

In order to test whether the blastomeres that normally are the progenitors of the DA nucleus are committed to this lineage, the major contributor to the nucleus (D1.1.1) was bilaterally deleted at the 32 -cell stage. $\Lambda$ bout $60 \%$ of the operated embryos completed the morphogenetic movements of gastrulation and 


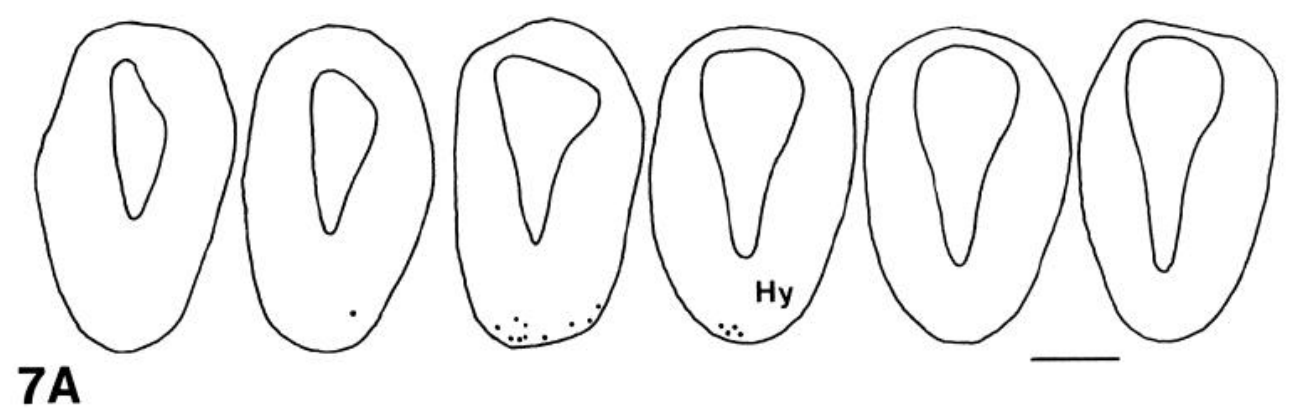

Figure 7. A, Camera lucida drawing of frontal sections of the forebrain of an embryo in which D1.1.1 had been deleted bilaterally. The brain is small and the infundibulum is missing (compare to Fig. 3). The DA neurons (solid circles) are fewer in number and are distributed along the ventralmost surface of the brain. $H y$, hypothalamus. $B, \mathrm{~A}$ photomicrograph of the ectopically located DA neurons. Arrowheads point to the ventral border of the forebrain. The arrow points to an autofluorescent cell. Scale bars: $A, 100 \mu \mathrm{m} ; B, 25 \mu \mathrm{m}$.

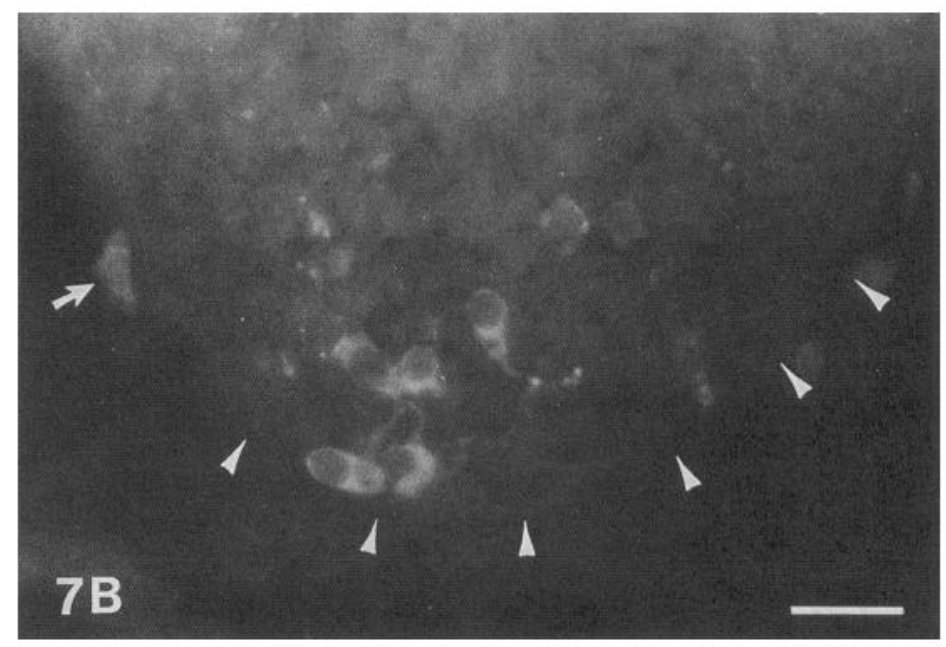

neurulation normally (Table 3); externally, they appeared nor$\mathrm{mal}$ and they displayed normal escape swimming. Nonetheless, in $26 \%$ of these cases the hypothalamus either was smaller than normal, was severely disorganized and undifferentiated, or contained a small or no infundibulum. In about a third of these $(N$

Table 2. The number of DA neurons that descends from each blastomere

\begin{tabular}{|c|c|c|c|c|}
\hline $\begin{array}{l}\text { Blastomere } \\
(N)\end{array}$ & $\begin{array}{l}\% \\
\text { Embryos } \\
\text { with } \\
\text { DA-TRA } \\
\text { cells }\end{array}$ & $\begin{array}{l}\text { Mean }^{a} \\
\text { number of } \\
\text { DA-TRA } \\
\text { cells } \\
( \pm \text { SD })\end{array}$ & $\begin{array}{l}\text { Range of } \\
\% \text { of total }\end{array}$ & $\begin{array}{l}\text { Adjusted } \\
\text { mean }^{b} \% \\
\text { of total }\end{array}$ \\
\hline (15) ipsi & 100 & $12.1(7.6)$ & $7.7-86.5$ & 56.9 \\
\hline contra & 60 & $10.9(8.1)$ & $6.9-68.9$ & 28.6 \\
\hline D1.1.1 (12) ipsi & 100 & $10.7(6.2)$ & $6.1-64.3$ & 41.7 \\
\hline contra & 67 & $6.0(3.9)$ & $6.5-41.2$ & 14.9 \\
\hline D1.1.2 (15) ipsi & 67 & $10.4(8.3)$ & $4.5-60.0$ & 22.4 \\
\hline contra & 47 & $5.7(3.2)$ & $3.0-37.5$ & 10.5 \\
\hline (12) ipsi & 50 & $6.3(4.9)$ & $8.0-45.7$ & 12.8 \\
\hline contra & 8 & $5.0(0)$ & - & 1.7 \\
\hline \multirow{2}{*}{$\begin{array}{r}\text { D1.2.1 (11) ipsi } \\
\text { contra }\end{array}$} & 27 & $3.3(2.3)$ & $6.7-18.8$ & 3.5 \\
\hline & 0 & - & - & - \\
\hline \multirow{2}{*}{$\begin{array}{r}\text { D1.2.2 (10) ipsi } \\
\text { contra }\end{array}$} & 40 & $4.3(2.5)$ & $3.3-18.4$ & 6.3 \\
\hline & 20 & $1.0(0)$ & $2.7-2.9$ & 0.7 \\
\hline
\end{tabular}

${ }^{a}$ Only embryos that produced DA neurons are included in these calculations. ${ }^{b}$ Only embryos that produced DA neurons are included in these calculations, and the mean values are normalized so that the sum from the progenitors at either the 16 - or 32 -cell stage equals $100 \%$.
$=11)$ the DA nucleus was either small or consisted of only a few DA neurons that were displaced along the ventral border of the brain (Fig. $7 ; \bar{x}=20.2 \pm 4.6$ ). No DA neurons were found in the diencephalon of the rest of the deficient embryos $(N=16)$ or in two cases with a normal-looking hypothalamus. In $72 \%$ of the specimens that completed normal morphogenesis $(N=74)$, the DA nucleus was restored to its normal size $(\bar{x}=$ $31.0 \pm 7.8$ ) by the remaining blastomeres.

To determine which blastomeres alter their production of DA neurons in response to D1.1.1 ablation, we injected one animal hemisphere cell with TRA just before the surgery and counted the number of DA neurons contained in the labeled clone. Two ventral animal blastomeres (V1.1.1 and V1.2.1), which normally do not contribute to the ventral forebrain, produced considerable numbers of DA neurons $(42 \%$ of the bilateral total; Fig. 8). One dorsal lateral blastomere (D1.2.1), which normally produces only a few DA neurons, significantly increased its contribution (Fig. 8). Finally, instead of compensating for the loss of D1.1.1's DA neuron lineage, its sister (D1.1.2) significantly decreased its production of DA neurons (from $33 \%$ to $10 \%$ ). D1.2.2 did not change its production of DA neurons, and other surrounding blastomeres (i.e., V1.2.2, V1.1.2, D2.1.2, D2.2.2) did not alter their normal lineages to contribute to the restoration of the DA nucleus.

\section{Discussion}

In several invertebrates, it has been possible to directly observe the mitoses leading from zygote to differentiated cells. In general, it has been found that a cell's genealogy can affect the determination of its phenotype in one of three patterns (Kenyon, 
Table 3. Restoration of the hypothalamus after bilateral ablation of D1.1.1

\begin{tabular}{lccl} 
Embryos in which: & $\begin{array}{l}\text { Num- } \\
\text { ber of } \\
\text { cases of }\end{array}$ & $\begin{array}{l}\text { \% of those } \\
\text { toth normal } \\
\text { gross } \\
\text { morphology }\end{array}$ \\
\hline D1.1.1 was ablated & 172 & 100 & - \\
Gross morpholugy was normal & 103 & 59.9 & 100 \\
Hypothalamus was normal & 76 & 44.2 & 73.8 \\
DA neurons were present & 85 & 49.4 & 82.5 \\
\hline
\end{tabular}

1985; Stent, 1985; Davidson, 1990). Cells expressing the same phenotype may (1) descend from a common precursor, (2) share equivalent lineal positions within the mitotic history, or (3) be placed in the appropriate position by their lineage to be induced by a spatially confined morphogen. Recent cell fate studies have elegantly demonstrated that common precursors rarely determine cell phenotype in the vertebrate CNS (reviewed in Harris and Holt, 1990; McConnell, 1991). However, techniques that randomly label neuroepithelial cells cannot address the other two possible roles of lineage. Because frog embryos provide specimens in which the early cleavages are identical, it has been possible for us to test which lineage pattern is important in the generation of a small, neurochemically defined cluster of neurons.

\section{Do all DA neurons descend from a single cleavage stage progenitor?}

One mechanism by which lineage can determine phenotype is to commit all descendants to a single cell type. This clonal pattern has been described in a number of tissues (Kenyon, 1985; Stent, 1985; Davidson, 1990). In the vertebrate nervous system, however, the only example so far is murine cortical glia, whose progenitors diverge from neuronal ones around embryonic days 12-14 (Luskin et al., 1988). The fact that all other marked clones reported contain multiple phenotypes has frequently been interpreted to mean that lineage plays no role in vertebrate CNS phenotype decisions. However, it is more accurate to conclude from these studies that a clonal pattern of determination is rare.

Similarly, in the extensive fate maps that have been made for the frog, no cleavage progenitor is the sole ancestor of a particular tissue or cell type (Hirose and Jacobson, 1979; Jacobson and Hirose, 1981; Dale and Slack, 1987; Moody, 1987a,b). For example, nearly every blastomere at the 16- and 32-cell stages produces at least some primary motor and sensory neurons (Moody, 1989) and primary GABAergic interneurons (Moody and Kersey, 1989). However, a global origin might be expected for cells that are distributed through nearly the entire length of the neuraxis. The present study demonstrates that the spatially restricted DA neurons of the hypothalamus are much more restricted with regard to their clonal origin; only four of the 16cell blastomeres contribute to the DA nucleus. However, this small cluster of neurons never descended exclusively from one 16-cell blastomere. D1.l was the major, but never the only, progenitor. Thus, just as has been demonstrated with clones initiated closer to the terminal branches of ncural lincages (e.g., Price et al., 1987; Turner and Cepko, 1987; Gray et al., 1988; Holt et al., 1988; Wetts and Fraser, 1988; Leber et al., 1990), single neural phenotypes do not derive from a single progenitor,
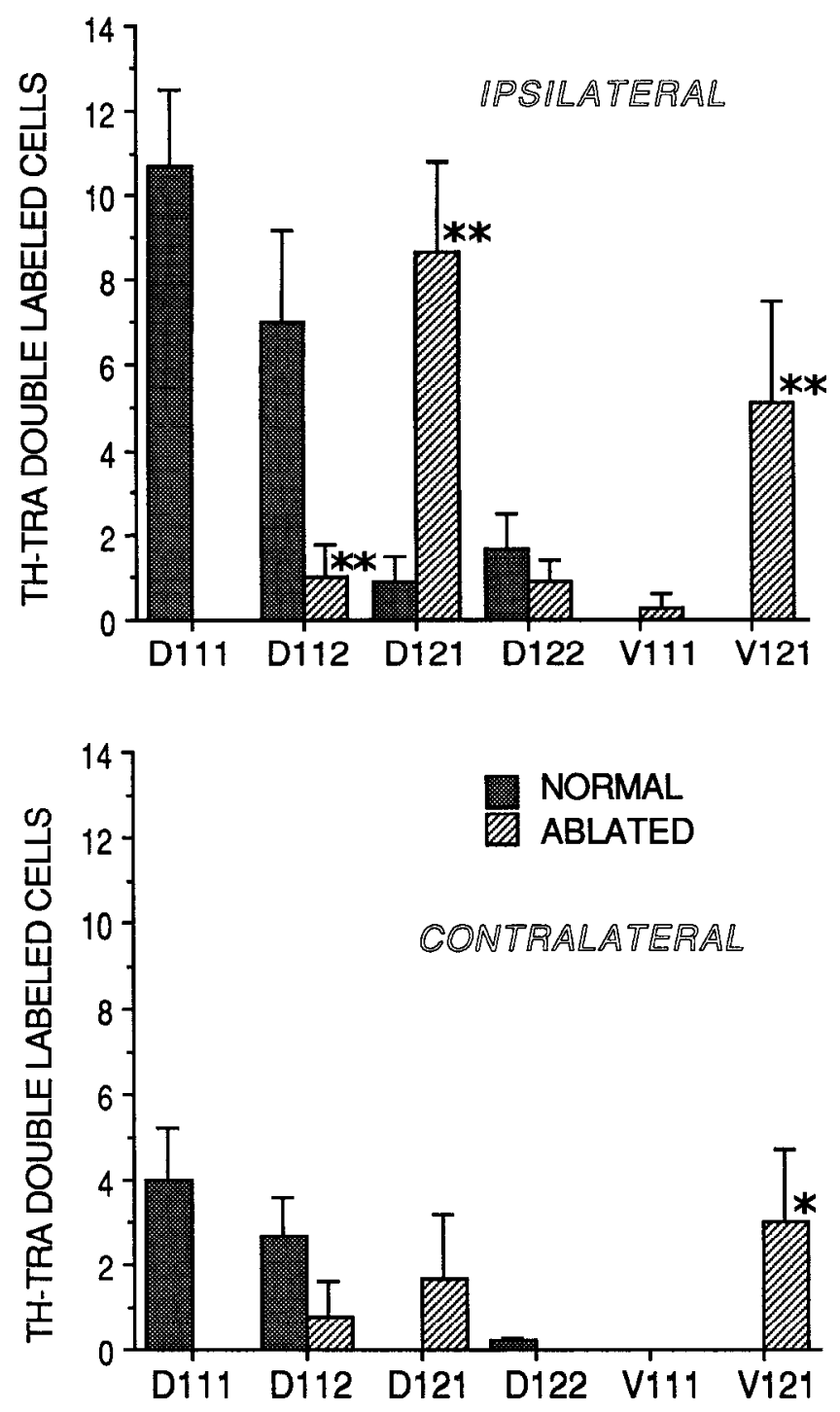

Figure 8. Histogram showing the contribution of the 32-cell stage blastomeres to DA nucleus in normal embryos (shaded) and in embryos in which the major DA progenitor (D1.1.1) was deleted bilaterally at the 32-cell stage (hatched). Note that the lineages of four blastomeres change significantly $\left({ }^{* *}, p<0.01 ;{ }^{*}, p<0.1\right)$. Blastomeres V1.2.2, V1.1.2, D2.1.2, and D2.2.2 also were tested, and none of them contributed DA neurons.

even when that progenitor produces as many as $1 / 16$ of the cells in the embryo.

Our study cannot directly address whether hypothalamic DA neurons clonally descend from one or a few precursors in the neural plate. Estimates of the number of cell cycles between neural plate and tadpole stages, based on the birthdate studies of others (Jacobson, 1968; Holt et al., 1988; Hartenstein, 1989), indicate that one neuroepithelial cell could produce 32-512 descendants and thus theoretically could produce the entire DA nucleus. However, our data show that this nucleus descends from four different cleavage stage blastomeres, and therefore from a mosaic of at least four different neuroepithelial cells. (A mosaic origin of another small nucleus, the mouse facial motor nucleus, also has been described; Herrup et al., 1984.) Whether any of these neuroepithelial cells produce clones consisting only of DA neurons can only be tested by direct injection of neural 
plate cells. Using this technique has shown that primary neuron progenitors at their last mitotic division in the spinal region of the Xenopus neural plate give rise to two daughters of the same phenotype in $76 \%$ of the clones (Hartenstein, 1989), suggesting that the final mitosis might be phenotypically determinative.

\section{Does the mitotic pattern determine the DA phenotype?}

Two techniques have been used to demonstrate that the mitotic pattern itself may determine cell phenotype: direct visualization of mitoses (e.g., Sulston and White, 1980; Sulston et al., 1983; Doe and Goodman, 1985) and labeling identified precursors with a lineage dye and demonstrating whether the descendants are the same from one animal to the next (reviewed in Stent and Weisblat, 1985). In Xenopus, the latter approach is possible for cleavage stage progenitors because the early cleavages frequently occur in a stereotyped pattern (Moody, 1987a,b). Fate maps using this technique have reported that lineage is very consistent but not invariant from one animal to another (Hirose and Jacobson, 1979; Jacobson and Hirose, 1981; Masho and Kubota, 1986; Dale and Slack, 1987; Moody, 1987a,b; Moody and Kline, 1990). The fate map for the DA nucleus agrees with these reports. Consistently, only four of the 16-cell blastomeres give rise to DA neurons. Of these four, however, only one of them (ipsilateral D1.1) does so in all specimens; the other blastomeres only produce DA neurons in half or fewer of the specimens. Thus, whether an "identified" cleavage stage blastomere produces DA neurons is probabilistic for the majority of the progenitors rather than determinate. This conclusion has also been reached for most tissues of the zebrafish embryo (Kimmel and Warga, 1987).

Another possibility is that the mitotic pattern determines the number of cells generated. For example, it has been suggested that vertebrate lineages may control the number of neuronal descendants (Williams and Herrup, 1988), a hypothesis that is supported by the observation that the number of Purkinje cells produced by a founder cell is different in different genetic strains of mice (Herrup, 1986; Herrup and Sunter, 1986). However, it is difficult to prove whether lineage controls cell number in vertebrates because we cannot trace mitotic histories, and the number of neurons within clones can be huge (e.g., $>10,000$ for C3H/HeJ Purkinje cells; Wetts and Herrup, 1982). Since we could mark the same progenitor in many different Xenopus embryos, and since the DA nucleus in the hypothalamus is small, we could test whether genealogy controls cell number of this phenotype in the frog forebrain. The wide range in the number of DA neurons that descended from the same blastomere in different embryos (Table 2) argues against any strict genealogical control of cell number. Those blastomeres whose clone coherently and densely populated the ventral forebrain gave rise to large numbers of DA neurons, whereas those blastomeres whose labeled cells mixed extensively with unlabeled ones and less densely populated the ventral forebrain gave rise to fewer DA neurons (Fig. 6). Thus, the fate to produce DA neurons probably results from whether the clone of a particular blastomere comes to reside in the right region of the neuroepithelium after the movements of gastrulation (Davidson, 1990) and slow mixing in the neural plate (Wetts and Fraser, 1989). The number of DA neurons produced by cleavage stage blastomeres is unlikely to be controlled by their mitotic patterns; however, direct labeling of the neuroepithelial precursors is needed to establish whether such control exists within neural plate sublineages.
Does lineage determine the DA phenotype by placing descendants in the right place for local determinative inductions?

Several studies of other regions of the CNS show that lineage can restrict spatial distribution rather than phenotype (Jacobson, 1983; Crandall and Herrup, 1990; Fishell et al., 1990; Fraser et al., 1990; Moody and Kline, 1990). As mentioned above, our data suggest that lineage influences DA fate in frogs by determining whether cells migrate into the hypothalamic region of the neural plate. Xenopus gastrulation movements are very stereotyped (Keller, 1975), and clones migrate coherently (Moody, 1985; Wetts and Fraser, 1989). It is possible that during this migration some cells may become committed, via local extracellular cues or intercellular interactions, to produce DA neurons. This mechanism has been suggested for frog proopiomelanocortin (POMC) neurons (Hayes and Loh, 1990) and by numerous studies of neural crest specification (LeDouarin, 1982), including those that express TH (Vogel and Weston, 1990). In addition, cell-cell interactions within the neuroepithelium may induce or inhibit specific neuronal phenotypes (McConnell, 1991). For example, insect neuroblasts inhibit neighboring cells from taking a neuroblast fate (Doe et al., 1985), in the vertebrate retina the types of cells that are generated depend upon the differentiated constituents already in place (Reh and Tully, 1986; Reh and Kljavin, 1989), and in the rat limbic system the regional environment of the cortical neuroepithelium may determine the molecular phenotype of early differentiating cells (Barbe and Levitt, 1991). Therefore, an important next step to take in understanding the determination of frog DA neurons is to characterize cellular environments and interactions during gastrula and neural tube stages. Although cell phenotype choice in some areas of the mammalian forebrain [e.g., septum (Temple, 1989) and hippocampus (Mattson et al., 1989)] does not seem to rely on environmental cues, this hypothesis needs to be tested in the frog.

\section{Are cleavage stage blastomeres committed to the $D A$ phenotype?}

If cleavage stage progenitors are determined and require no further intercellular interactions to produce DA neurons, then removal of one of the progenitors should (1) produce a deficit in the total DA population and (2) not affect the lineages of the remaining DA progenitors. Indeed, some cleavage blastomeres are determined with regard to dorsal fate as early as the 16-cell stage (Gallagher et al., 1991). In our study, bilateral ablation of the major DA neuron progenitor resulted in two groups of embryos: in one group the hypothalamus was significantly reduced in size or missing, and in the other group the forebrain, including the DA nucleus, appeared quite normal. Thus, at least some of the remaining cells are competent to restore the DA nucleus, but are not always successful in doing so. It seems unlikely that nonspecific damage during the surgery prevented regulation in the first group because we eliminated those individuals in which such damage was obvious from our study (Table 3). However, since cell-cell signaling, gap junctional communication, and blastomere position are all known to be important during the cleavage stages (Davidson, 1990), subtle perturbations of these events may have prevented some embryos from reconstituting the ventral forebrain.

In those embryos that regulated to produce a normal appearing forebrain, many animal hemisphere blastomeres changed 
the number of DA neurons they produced to restore the DA nucleus nearly to its normal size. One cell decreased its contribution, but three others significantly increased their contribution. Two of these latter cells were novel progenitors in that normally they never contribute to the forebrain at all. These results indicate that the DA lineage is not determined at the early cleavage stages. Rather, the relocation of the descendants of the regulating blastomeres during gastrulation may have signaled their change in fate (Davidson, 1990). As mentioned above, blastomere origin may affect whether descendants migrate into the correct position of the neural plate so that they can respond to local environmental signals that will induce the DA phenotypc. If this is true, then changes in position due to the reorganization of gastrulation movements after D1.1.1 ablations may induce new progenitors to express the DA fate. We are studying this possibility by mapping the gastrulation/neurulation movements of the clones of DA neuron progenitors in normal and regulating embryos. It should be noted that not all animal hemisphere blastomeres were induced to produce DA neurons. This may be because only a subset of blastomeres are competent to produce DA neurons, or that all blastomeres are competent but not all migrate through the appropriate regions, even after D1.1.1 ablations, to become induced to express the DA fate. These possibilities are now being tested.

\section{References}

Barbe MF, Levitt P (1991) The early commitment of fetal neurons to the limbic cortex. J Neurosci 11:519-533.

Blair SS, Martindale MQ, Shankland M (1990) Interactions between adjacent ganglia bring about the bilaterally alternating differentiation of RAS and CAS neurons in the leech nerve cord. J Neurosci 10: 3183-3193.

Crandall JE, Herrup K (1990) Patterns of cell lineage in the cerebral cortex reveal evidence for developmental boundaries. Exp Neurol 109:13.1-139.

Dale L, Slack JMW (1987) Fate map for the 32-cell stage of Xenopus lacvis. Development 99:527-551.

Davidson EH (1990) How embryos work: a comparative view of diverse modes of cell fate specification. Development 108:365-389.

Doe CQ, Goodman C (1985) Early events in insect neurogenesis. II. The role of cell interactions and cell lineage in the determination of neuronal precursor cells. Dev Biol 111:206-219.

Doe CQ, Kuwada JY, Goodman CS (1985) From epithelium to neuroblasts to neurons: the role of cell interaction and cell lineage during insect neurogenesis. Philos Trans R Soc Lond [Biol] 312:67-81.

Fishell G, Rossant J, van der Kooy D (1990) Neuronal lineages in chimeric mouse forebrain are segregated between compartments and in the rostrocaudal and radial planes. Dev Biol 141:70-83.

Franzoni MF, Thibault J, Fasolo A, Martinoli MG, Scaranari F, Calas A (1986) Organization of tyrosine-hydroxylase immunopositive neurons in the brain of the crested newt, Triturus cristatus carnifex. J Comp Neurol 251:121-134.

Fraser S, Keynes R, Lumsden A (1990) Segmentation in the chick embryo hindbrain is defined by cell lineage restrictions. Nature 344: $431-435$.

Galileo DS, Gray GE, Owens GC, Majors J, Sanes JR (1990) Neurons and glia arise from a common progenitor in chicken optic tectum: demonstration with two retroviruses and cell type-specific antibodies. Proc Natl Acad Sci USA 87:458-462.

Gallagher BC, Hainski AM, Moody SA (1991) Autonomous differentiation of dorsal axial structures from an animal cap cleavage stage blastomere in Xenopus. Development 112:1103-1114.

Gray GE, Glover JC, Majors J, Sanes JR (1988) Radial arrangement of clonally related cells in the chicken optic tectum: lineage analysis with a recombinant retrovirus. Proc Natl Acad Sci USA 85:73567360.

Harris WA, Holt CE (1990) Early events in the embryogenesis of the vertebrate visual system: cellular determination and pathfinding. Annu Rev Neurosci 13:155-169.
Hartenstein V (1989) Early neurogenesis in Xenopus: the spatio-temporal pattern of proliferation and cell lineages in the embryonic spinal cord. Neuron 3:399-411.

Hayes WP, Loh YP (1990) Correlated onset and patterning of proopiomelanocortin gene expression in embryonic Xenopus brain and pituitary. Development 110:747-757.

Herrup K (1986) Cell lineage relationships in the development of the mammalian CNS: role of cell lineage in control of cerebellar Purkinje cell number. Dev Biol 115:148-154.

Herrup K, Sunter K (1986) Cell lineage dependent and independent control of Purkinje cell number in the mammalian CNS: further quantitative studies of lurcher chimeric mice. Dev Biol 117:417-427.

Herrup K, Diglio TJ, Letsou A (1984) Cell lineage relationships in the development of the mammalian CNS. I. The facial nerve nucleus. Dev Biol 103:329-336.

Hirose G, Jacobson M (1979) Clonal organization of the central nervous system of the frog. I. Clones stemming from individual blastomeres of the 16-cell and earlier stages. Dev Biol 71:191-202.

Holt CE, Bertsch TW, Ellis HM, Harris WA (1988) Cellular determination in the Xenopus retina is independent of lineage and birthdate. Neuron 1:15-26.

Jacobson M (1968) Cessation of DNA synthesis in retinal ganglion cells is correlated with the time of specification of their central connections. Dev Biol 17:219-232.

Jacobson M (1981) Rohon-Beard neuron origin from blastomeres of the 16-cell frog embryo. J Neurosci 1:918-922.

Jacobson M (1983) Clonal organization of the central nervous system of the frog. III. Clones stemming from individual blastomeres of the 128-, 256- and 512-cell stages. J Neurosci 3:1019-1038.

Jacobson M, Hirose G (1981) Clonal organization of the central nervous system of the frog. II. Clones stemming from individual blastomeres of the 32- and 64-cell stages. J Neurosci 1:271-284.

Keller RE (1975) Vital dye mapping of the gastrula and neurula of Xenopus laevis. I. Prospective areas and morphogenetic movements of the superficial layer. Dev Biol 42:222-241.

Kenyon C (1985) Cell lineage and the control of Caenorhabditis elegans development. Philos Trans R Soc Lond [Biol] 312:21-38.

Kimmel CB, Warga RM (1987) Indeterminate cell lineage of the zebrafish embryo. Dev Biol 124:269-280.

Klein SL (1987) The first cleavage furrow demarcates the dorsal-ventral axis in Xenopus embryos. Dev Biol 120:299-304.

Lamas J, Rodicio C, Caruncho H, Anadon R (1988) Monoaminergic systems of the hypothalamus of ten amphibian species: a histofluorescence study. J Hirnforsch 29:289-297.

Leber SM, Breedlove SM, Sanes JR (1990) Lineage, arrangement, and death of clonally related motoneurons in chick spinal cord. J Neurosci 10:2451-2462.

LeDouarin N (1982) The neural crest. Cambridge: Cambridge UP.

Luskin MB, Pearlman AL, Sanes JR (1988) Cell lineage in the cerebral cortex of the mouse studied in vivo and in vitro with a recombinant retrovirus. Neuron 1:635-647.

Masho R (1988) Fates of animal dorsal blastomeres of eight-cell stage Xenopus embryos vary according to the specific patterns of the third cleavage plane. Dev Growth Differ 30:347-359.

Masho R (1990) Close correlation between the first cleavage plane and the body axis in early Xenopus embryos. Dev Growth Differ 32: 57-64.

Masho R, Kubota HY (1986) Developmental fates of blastomeres of eight-cell-stage Xenopus laevis embryos. Dev Growth Differ 28:113123.

Mattson MP, Guthrie PB, Hayes BC, Kater SB (1989) Roles for mitotic history in the generation and degeneration of hippocampal neuroarchitecture. J Neurosci 9:1223-1232.

McConnell SK (1991) The generation of neuronal diversity in the central nervous system. Annu Rev Neurosci 14:269-300.

Moody SA (1985) Gastrulation movements of progeny derived from 16-cell stage Xenopus blastomeres. J Cell Biochem 9B:275.

Moody SA (1987a) Fates of the blastomeres of the 16-cell stage Xenopus embryo. Dev Biol 119:560-578.

Moody SA (1987b) Fates of the blastomeres of the 32-cell stage Xenopus embryo. Dev Biol 122:300-319.

Moody SA (1989) Quantitative lineage analysis of the origin of frog primary motor and sensory neurons from cleavage stage blastomeres. J Neurosci 9:2919-2930.

Moody SA, Huang S (1990) Development of primary and secondary 
tyrosine hydroxylase positive cells in Xenopus. Soc Neurosci Abstr 16:174.

Moody SA, Kersey KL (1989) Clonal analysis of GABAergic neurons in the frog spinal cord. Soc Neurosci Abstr 15:885.

Moody SA, Kline MJ (1990) Segregation of fate during cleavage of frog (Xenopus laevis) blastomeres. Anat Embryol 182:347-362.

Moody SA, Quigg MS, Little CD (1989) Extracellular matrix components of the peripheral pathway of chick trigeminal axons. J Comp Neurol 283:38-53.

Nicola NA, Johnson GR (1982) The production of committcd hcmatopoietic colony-forming cells from multipotential precursor cells in vitro. Blood 61:823-829.

Nieuwkoop PD, Faber J (1964) Normal table of Xenopus laevis (Daudin), 2d ed. Amsterdam: Elsevier-North Holland.

Nishida H, Satoh N (1985) Cell lineage analysis in ascidian embryos by intracellular injection of a tracer enzyme. II. The 16- and 32-cell stages. Dev Biol 110:440-454.

Parent A (1979) Anatomical organization of monoamine and acetylcholinesterase-containing neuronal systems in the vertebrate hypothalamus. In: Anatomy of the hypothalamus, Vol 1 (Morgane PJ, Panksepp J, eds), pp 511-544. New York: Dekker.

Price J, Turner D, Cepko C (1987) Lineage analysis in the vertebrate nervous system by retrovirus-mediated gene transfer. Proc Natl Acad Sci USA 84:156-160.

Reh TA, Kljavin IJ (1989) Age of differentiation determines rat retinal germinal cell phenotype: induction of differentiation by dissociation. J Neurosci 9:4179-4189.

Reh TA, Tully T (1986) Regulation of tyrosine-hydroxylase-containing amacrine cell number in the larval frog retina. Dev Biol 114:463469.

Roux W (1888) Beitrage zur Entwicklungsmechanik des Embryo. Virchows Arch Pathol Anat Physiol Klin Med 114:113-153. Reprinted in: Foundations of experimental embryology (Willier BH, Oppenheimer JM, eds; Laufer H, transl), pp 2-37. New York: Hafner, 1974.

Sims TJ (1977) The development of monoamine-containing neurons in the brain and spinal cord of the salamander, Ambystoma mexicanum. J Comp Neurol 173:319-336.
Stent G (1985) The role of cell lineage in development. Philos Trans R Soc Lond [Biol] 312:3-19.

Stent G, Weisblat DA (1985) Cell lineage in the development of invertebrate nervous systems. Annu Rev Neurosci 8:45-70.

Sternberg PW, Horvitz HR (1984) The genetic control of cell lineage during nematode development. Annu Rev Genet 18:489-524.

Sulston JE, White JG (1980) Regulation and cell autonomy during postembryonic development of Caenorhabditis elegans. Dev Biol 78: 577-597.

Sulston JE, Schicrenberg E, White JG, Thomson JN (1983) The embryonic cell lineage of the nematode Caenorhabditis elegans. Dev Biol 100:64-119.

Temple S (1989) Division and differentiation of isolated CNS blast cells in microculture. Nature 340:471-473.

Terlou M, Ploemacher RE (1973) The distribution of monoamines in the tel-, di- and mesencephalon of Xenopus laevis tadpoles, with special reference to the hypothalamo-hypophysial system. Z Zellforsch 137:521-540.

Turner DL, Cepko CL (1987) A common progenitor for neurons and glia persists in rat retina late in development. Nature 328:131-136.

Vogel KS, Weston JA (1990) The sympathoadrenal lineage in avian embryos. II. Effects of glucocorticoids on cultured neural crest cells. Dev Biol 139:13-23.

Wetts R, Fraser SE (1988) Multipotent precursors can give rise to all major cell types of the frog retina. Science 239:1142-1145.

Wetts R, Fraser SE (1989) Slow intermixing of cells during Xenopus embryogenesis contributes to the consistence of the blastomere fate map. Development 105:9-15.

Wetts R, Herrup K (1982) Cerebellar Purkinje cells are descended from a small number of progenitors committed during early development: quantitative analysis of lurcher chimeric mice. J Neurosci 2:1494-1498.

White JG, Horvitz HR, Sulston JE (1982) Neuron differentiation in cell lineage mutants of Caenorhabditis elegans. Nature 297:584-589.

Williams RW, Herrup K (1988) The control of neuron number. Annu Rev Neurosci 11:423-453. 